\title{
Interação, engajamento e crowdsourcing: um estudo do caso The Johnny Cash Project
}

\author{
Interaction, engagement and crowdsourcing: a study of case The Johnny Cash \\ Project
}

Interacción, compromiso y crowdsourcing: unestudio del casoThe Johnny Cash Project

\author{
Cristiano Max Pereira Pinheiro ${ }^{l}$ \\ André Conti Silva \\ Mauricio Barth ${ }^{3}$ \\ Jeison Pacheco ${ }^{4}$ \\ http://dx.doi.org/10.5216/33738
}

\section{Resumo}

Com o surgimento da Internet e a evolução da Web 2.0, os usuários ganharam maior autonomia para a geração de conteúdo, fato que culminou com o surgimento de novas plataformas que apresentam inúmeras possibilidades de produção de material. Tais ambientes, com conteúdos criados pelos próprios usuários, atraem cada vez mais o interesse de participantes ao redor do mundo. Sendo assim, o presente estudo buscouanalisar como se deram as dinâmicas de colaboração na Web 2.0 através da coautoria dos usuários no projeto onlineThe Johnny Cash Project.

Palavras-chave: Interação. Engajamento. Crowdsourcing. The Johnny Cash Project.

\begin{abstract}
With the emergence of the Internet and the evolution of Web 2.0, users gained greater autonomy for content generation, a fact that led to the emergence of new platforms that present numerous opportunities for production material. Such environments, with content created by the users, are increasingly attracting the interest of participants around the world. Therefore, this study aimed to analyze how have the dynamics of collaboration in Web 2.0 through co-authorship of users in the online project The Johnny Cash Project.
\end{abstract}

Keywords: Interaction. Engagement. Crowdsourcing. The Johnny Cash Project.

\section{Resumen}

Conlaaparición de Internet y de laevolución de la Web 2.0, losusuariosobtuvieron una mayorautonomía para lageneración de contenidos, unhecho que llevó a laaparición de nuevas plataformas que presentan numerosas oportunidades para material de producción. Tales ambientes, concontenidocreado por losusuarios, estánatrayendo cada vez más elinterés de los participantes de todo el mundo. Por lo tanto, este estudiotuvo como objetivo analizarcómotieneladinámica de

\footnotetext{
${ }^{1}$ Doutor pela Pontifícia Universidade Católica do Rio Grande do Sul (PUCRS), Mestre em Comunicação Social pela Pontifícia Universidade Católica do Rio Grande do Sul (PUCRS). Professor do Mestrado de Indústria Criativa da Universidade FEEVALE. Brasil, Rio Grande do Sul (RS), Novo Hamburgo. E-mail: maxrs@feevale.br

${ }^{2}$ Doutor pela Universidade Federal do Rio Grande do Sul (UFRGS). Mestre em Design pela Universidade do Vale do Rio dos Sinos (UNISINOS). Membro do grupo de pesquisa Laboratório de Artefatos Digitais (LAD) da UFRGS. Brasil, Rio Grande do Sul (RS), Novo Hamburgo. E-mail: andrec@feevale.br

${ }^{3}$ Mestrando em Indústria Criativa na Universidade FEEVALE. Especialista em Gestão Estratégica de Marketing pela Universidade FEEVALE. Brasil, Rio Grande do Sul (RS), Novo Hamburgo. E-mail: mauricio@feevale.br

${ }^{4}$ Graduado em Publicidade e Propaganda pela Universidade FEEVALE. Brasil, Rio Grande do Sul (RS), Novo Hamburgo.
}

Comun. \& Inf., Goiânia, GO, v. 18, n. 1, p. 76-96,jan./jun. 2015 
lacolaboraciónenlaWeb 2.0 através de co-autoría de losusuariosenelproyecto online The Johnny Cash Project.

Palabras clave:Interacción. Compromiso. Crowdsourcing. The Johnny Cash Project.

\section{INTRODUÇÃO}

7 om a popularização das ferramentas da Web 2.0, que, em sua maioria, são gratuitas e de fácil manuseio por parte dos internautas, observa-se um cenário no qual o conteúdo gerado por pessoas comuns prolifera pela Internet. Esse conteúdo, que pode ser textos, imagens, sons e vídeos, é facilmente acessível por todos, via buscadores ou outros sistemas de compartilhamento de sites.

Segundo dados divulgados pelo Instituto Brasileiro de Geografia e Estatística (IBGE, 2013), mais da metade dos brasileiros já está conectada à Internet. As informações fazem parte da Pesquisa Nacional por Amostra de Domicílios (PNAD) do ano de 2013. Ainda, de acordo com o IBGE (2013), o Brasil ganhou 2,5 milhões de internautas (2,9\%) entre 2012 e 2013, totalizando, aproximadamente, 86,7 milhões de usuários com acesso à Internet com 10 anos ou mais no país.

Através de uma pesquisa publicada pelo IBOPE (2013), o Brasil apresenta a terceira maior taxa de utilização da Web 2.0 em usuários que acessam a rede quase que diariamente. O mesmo estudo aponta o país como líder no ranking mundial no que se refere às comunidades online, espaços onde cada vez mais se compartilham experiências de consumo. Dos mais de 52 milhões de usuários regulares da internet no Brasil (que além de possuir acesso, navegam quase diariamente), $64 \%$ participam de redes sociais e $13 \%$ criam ou atualizam blogs.

Se o crescente número de usuários na Web 2.0 proporciona, cada vez mais, interações e colaborações no mundo digital, o número de plataformas que possuem esses tipos de características crescem no mesmo sentido. Igualmente, as formas de colaboração presentes na Web 2.0 também evoluem, proporcionando o surgimento de novas ferramentas, como o crowdsourcing.

Dessa forma, o enfoque deste estudo está ligado às novas formas de colaboração na Web 2.0, e utiliza-se da metodologia de estudo de caso para analisar esse cenário. Como objeto de estudo, o projeto póstumo em homenagem ao cantor Johnny Cash, o The Johnny Cash Project, foi escolhido por ter sido umadas primeiras plataformas a emaranhar o consumo de videoclipe de música com a ferramenta de crowdsourcing. Além disso, cada visualização do projeto pode ser considerada única, pois a combinação de frames enviados pelos usuários 
口FIC

para o vídeo provavelmente nunca se repetirá, devido à sua expressiva quantidade de colaborações. Mesmo lançado em 2010, The Johnny Cash Project ainda movimenta milhares de acessos ao ano, além de diversos comentários em outras plataformas.

\section{COLABORAÇÃO NA WEB}

A evolução da web trouxe várias mudanças para a sociedade; entre essas, umas demostram-se mais fundamentais do que as outras. Com o passar do tempo, a colaboração tornou-se umas das principais ferramentas da Web 2.0. Assim sendo, para dar prosseguimento ao estudo, é necessário entender alguns aspectos que cercam e intensificam a colaboração em meio digital. A presente seção tem como foco descrever e contextualizar a colaboração na web, assim como o conceito de interatividade e de engajamento, de forma que seja claro o entendimento dos mesmos para prosseguirmos com o surgimento do crowdsourcing.

A mudança mais significativa sentida pela sociedade através da evolução da web foi, de acordo com Recuero $(2009$, p. 24), “a possibilidade de expressão e sociabilização através das ferramentas de comunicação mediadas pelo computador". Nesse contexto, o surgimento das ferramentas comumente tidas como "Web 2.0", assim como os blogs, wikis, fóruns e redes sociais, descentralizou a participação na rede.

Para Castro (2011, p. 01), “o mundo está vivendo a era C: colaboração, conectividade, compartilhamento de conhecimentos, co-criação". Referente à colaboração e sistemas colaborativos, Camargo, Khouri e Guardiola (2005) contextualizam que um dos seus objetivos é diminuir as "barreiras" físicas e temporais.

Conforme O’Reilly (2005, p. 03) a colaboração é uma das principais ferramentas da Web 2.0, pois para ele, esta web é a "mudança para uma Internet como plataforma, e um entendimento das regras para obter sucesso nessa novaplataforma. Uma das principais regras é a criação de aplicativos que aproveitem a inteligência humana através da colaboração”.

Nos dias de hoje, onde o tempo é o "bem" mais escasso e as pessoas estão ocupadas, mas, ainda assim, encontram tempo para compartilhar conhecimento na web, "o que as motiva não é dinheiro nem reconhecimento, mas a sensação de estarem inseridas no mundo, [...], de se expressar, transformar e trocar ideias que merecem ser espalhadas" (GIARDELLI, 2012, p. 21). Segundo o autor, para estas pessoas, também existe a alegria de fazer algo em prol do outro, em "colaborar".

Para Giardelli (2012), é errôneo o pensamento no qual estar online "trancado em casa" é sinônimo de isolamento social e solidão, pois, devido à tecnologia, as pessoas estão se unindo e gerando encontros reais em massa. Assim sendo, para o autor, a web é a melhor

Comun. \& Inf., Goiânia, GO, v. 18, n. 1, p. 76-96,jan./jun. 2015 
ferramenta de relacionamento da humanidade, pois ela proporciona, dentre outras coisas, a explosão dos contatos entre pessoas, que propiciam de "networkinga namoros", de "revoluções à mudanças" e de "encontros à socialização". Para o autor (p. 22), "relacionar-se, conectar-se e compartilhar são atitudes fundamentais para o ser humano".

O aumento do número de colaborações na web têm afetado também os negócios, não somente a vida privada dos usuários (GIARDELLI, 2012). Para o autor, o comércio que despreza novos canais digitais está ficando para trás, pois a comunicação que não considera o coletivo e as redes sociais já é ineficiente.

Segundo Tapscott e Williams (2007, p. 44), atualmente a web está se transformando em um "computador gigante que todos podem programar, fornecendo uma infraestrutura global para a criatividade, a participação, o compartilhamento e a auto-organização". Da mesma forma, os autores complementam que se existe um princípio que define o que é a nova web, esse princípio é o de construção coletiva.

As transformações passadas pela web estão fazendo com que as pessoas possam pensar de maneira mais "colaborativa, plural e aberta" (LÉVY, 2000). Para Castro (2011), modelos de produção como o crowdsourcing utilizam a inteligência coletiva e a troca de conhecimentos em busca de algo novo, e esse é um grande exemplo de colaboração estimulada na Internet, e só realmente possível em esfera mundial graças a ela.

Para entendermos, por fim, o conceito de crowdsourcing, é preciso antes discutir olhares acerca de interatividade e os motivos pelos quais as pessoas se engajam em projetos quando não há um retorno financeiro ou mercantil.

\subsection{INTERATIVIDADE}

Um dos aspectos mais importantes na relação do ser humano com o computador é a chamada interatividade. Dessa forma, para Lemos (2010), interatividade é, atualmente, uma palavra do mundo das mídias eletrônicas. Praticamente tudo "se vende" como interativo; mas, hoje, destacam-se como redes interativas a Internet, jogos eletrônicos, televisões e cinema. Segundo o autor (p. 01), “o que compreendemos hoje por interatividade, nada mais é que uma nova forma de interação técnica, de cunho 'eletrônico-digital', diferente da interação 'analógica' que caracterizou as mídias tradicionais".

A TV tradicional é um meio que permite pouca interatividade, com os usuários podendo, somente, realizar simples ações como "mudar de canal" e "aumentar o volume" (MARQUES; CARDOSO, 2011). Assim sendo, para as autoras (p. 02) foi somente a partir de

Comun. \& Inf., Goiânia, GO, v. 18, n. 1, p. 76-96,jan./jun. 2015 
1995, entretanto, que essa realidade se alterou, pois a "TV interativa digital [..] passa a oferecer ao telespectador diversos programas interativos, e esse pode escolher, por exemplo, de qual câmera ele acompanhará um evento esportivo, a televisão passa a ser hipermídia". Dessa forma, Marques e Cardoso (2011) acrescentam que a leitura de um texto hipermídia pode ser feita de formas diferentes, de modo "não-linear" e apresentando diversas interpretações.

Esta também é a posição de Primo (2007) sobre interatividade, pois ele destaca que a mesma pode ocorrer por qualquer meio de comunicação, sendo ele um livro, jornal, rádio, televisão, entre outros, em sentido único, sendo o fluxo de "comunicação monológico". Thompson (2002, p. 79) reafirma a posição de Marques e Cardoso (2011) e Primo (2007), pois, para o autor, "o leitor de um livro é um receptor de uma forma simbólica cujo remetente não exige (e geralmente não recebe) uma resposta direta e imediata".

Se para Thompson (2002) as novas formas de interação sociais se dão através do desenvolvimento dos nossos meios de comunicação, de acordo comCanclini (2008, p. 55), as redes virtuais ainda "alteram os modos de ver e ler, as formas de reunir-se, falar e escrever, de amar e saber-se amado à distância, ou talvez, imaginá-lo".

A fim de aprofundar o conhecimento sobre interatividade, é necessário buscar a origem do sentido da palavra. Segundo Fragoso (2001, p. 02) “a palavra interatividade, derivada do neologismo inglês interactivity, foi cunhada para denominar uma qualidade específica da chamada computação interativa (interactivecomputing)".

Santaella (2004) afirma que uma das principais características da tecnologia digital, potencializada pela "configuração informacional em rede", "é permitir que os meios de comunicação possam atingir os usuários e obter um feedback imediato" (p. 150). Dessa forma, para o autor, neste tipo de ambiente online, nos quais os usuários têm uma participação mais direta, mais interativa, ocorre uma resposta do receptor (usuário) ao fazer uma leitura do conteúdo assistido e que foi postado por um emissor (também usuário). Recuero (2009) afirma que a interação só pode ser percebida devido aos rastros sociais que permanecem na Internet, quando os mesmos não são deletados.

Dessa forma, Primo (2007) conclui que é necessário olhar para o relacionamento na relação de interação social, pois sempre há certo contexto envolvido entre os "interagentes" que estão se comunicando. Essas novas formas de expressão e relacionamento são mutáveis, fazendo com que a relação interpessoal na web venha mudando com o avanço de novas tecnologias. 
Segundo Limeira (2003, p. 56), a interatividade possibilitada pela web "permite aprofundar o relacionamento entre as empresas e seus consumidores em várias etapas do programa de marketing", como na criação e desenvolvimento de produtos e serviços, na pesquisa de comportamento e desejos dos clientes, na avaliação da qualidade dos programas de marketing, na customização de produtos e serviços, na negociação de prazos e condições de pagamento, na comunicação de marketing, entre outras atividades empresariais.

Se a interatividade proporcionada pela Web 2.0 auxilia o mercado de comunicação e o relacionamento entre empresas e consumidores, faz-se necessário entender as motivações pelas quais os usuários se engajam em maior número nesta“"nova web”. Para tal entendimento, a seguir será abordado o conceito de "engajamento".

\subsection{ENGAJAMENTO}

Outro aspecto essencial para discutir fenômenos da Web 2.0 é o engajamento. Para compreender os motivos pelos quais as pessoas decidem se envolver em projetos ou atividades na web, é necessário verificar quais são as suas motivações e se há alguma recompensa financeira que pode influenciar no número de participantes. Ao mesmo tempo, é necessário descobrir se esta participação de uma "cultura" engajada auxilia no desenvolvimento de objetivos de negócios e/ou resolver problemas gerais.

Sobre engajamento, Moura (2011, p. 21) acredita que a sua definição vem do "francês engager [...], a palavra engajamento tem como significados: incitar, instigar, envolver ou levar alguém a se dedicar a alguma coisa ou causa". O número crescente das plataformas colaborativas "despertou o interesse do consumidor global a participar de campanhas, promoções e atividades lúdicas on-line" (p. 21).

Ao contrário do que se pode imaginar, não há relação alguma entre engajamento e recompensa financeira. Para Pink (2009, p. 07),“quando o dinheiro é utilizado como uma recompensa externa para alguma atividade, os indivíduos perdem o interesse intrínseco para a atividade". Da mesma forma (p. 07), recompensas podem entregar um "boost" de curto prazo, como uma "sacudida de cafeína" pode mantê-lo acionado por mais algumas horas. Mas o efeito desaparece, e, pior, pode reduzir a motivação de longo prazo de uma pessoa para continuar o projeto. Segundo o autor, "aquele que tem interesse em desenvolver e aumentar a motivação intrínseca em crianças, funcionários, estudantes, etc, não deve concentrar-se em sistemas de controle externo, tais como recompensas monetárias" (PINK, 2009, p. 08). Nesse sentido, Anderson (2006) levanta questões relevantes dos motivos pelos quais os indivíduos, 
口些

sem nenhuma perspectiva de remuneração, criam algo de valor. Segundo o autor, as razões podem variar, sendo desde uma forma de expressão, ou, puramente diversão, experimentação dos internautas, entre outras.

Seguindo a linha de raciocínio do autor, percebe-se que a maioria das empresas não se deu conta dessa nova compreensão do que motiva as pessoas. Muitas organizações, e não apenas as empresas, mas,também, governos e organizações sem fins lucrativos, ainda operam $\begin{array}{llllll}\text { a partir } & \text { de } & \text { suposições } & \text { sobre } & \text { o } & \text { potencial }\end{array}$ humanoedesempenhosindividuaisaparentementedesatualizados,sem comprovações, e enraizados mais "nos mitos" do que na ciência. Conforme Pink (2009), eles continuam a exercer práticas como a de planos de incentivo a curto prazo e de esquemas de remuneração por desempenho - que funcionam melhor em atividades que não envolvem muito a atividade de "pensar" - em detrimento da crescente evidência de que essas medidas geralmente não funcionam e que frequentemente causam danos. Pior ainda, segundo o autor, "essas práticas têm se infiltrado em nossas escolas, onde 'dobram' nossa futura força de trabalho com iPods, dinheiro e cupons de pizza para os 'incentivar' a aprender. Algo deu errado" (p. 09). Para ele, a motivação é pessoal e em geral, o motivo financeiro geralmente não influencia no engajamento de algo, explicando o porquê de as pessoas passarem tanto tempo tocando instrumentos musicais, montando quebra-cabeças nos finais de semana ou fazendo algo em prol do coletivo, sem receber nada em troca.

Para Brabham (2013), uma das coisas mais notáveis que surgiram na Web 2.0 não são as ferramentas, mas as formas nas quais as tecnologias advindas das "novas mídias" redefiniram as relações interpessoais. Para ele, a web já tem sido um lugar para a "cultura participativa" desenvolver-se, mas, no início dos anos 2000, viu-se pela primeira vez o surgimento de interesse das organizações de alavancar a inteligência coletiva das comunidades online para servir a objetivos de negócios e/ou resolver problemas gerais. Para o autor, este processo de obtenção de serviços, ideias ou conteúdos necessários solicitando contribuições de um grupo distinto de pessoas e, especialmente, a partir de uma comunidade online, pode ser denominado "crowdsourcing".

\subsection{CROWDSOURCING}

Segundo Howe (2009), ocrowdsourcingconsiste em repassar uma tarefa tradicionalmente realizada por um único empregado ou empresa para um indefinido e, geralmente, numeroso grupo de pessoas, com a expectativa de fornecer informações mais

Comun. \& Inf., Goiânia, GO, v. 18, n. 1, p. 76-96,jan./jun. 2015 


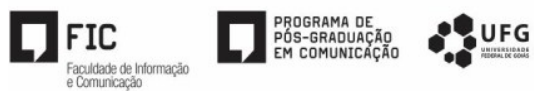

precisas e eficientes doque se fosse executada por um especialista da área. Dessa forma, o crowdsourcing não avalia formação, capacidade técnicae, sim, a qualidade do trabalho.

Mesmo o crowdsourcing sendo uma prática utilizada em várias áreas, é na tecnologia, que ele é mais disseminado. Isso se deve à sua origem, já que softwares open sources, como o Linux e o Firefox foram os pioneiros na utilização desta prática. Quando você visita a web para "verificar a previsão do tempo" ou "encomendar alguns tênis", você pode estar usando o Firefox, um navegador web gratuito de código aberto criado quase exclusivamente por voluntários ao redor do mundo, que possui mais de 150 milhões de usuários.

Contudo, Crowdsourcingnão é um processo exclusivamente online, já que o mesmotambém pode ocorrer em meios offline(HOWE, 2009). Segundo o autor, este processo é, frequentemente, utilizado para subdividir um trabalho tedioso, uma pesquisa, levantar fundos para empresas iniciantes e instituições de caridade. Ele combina os esforços de voluntários ou trabalhadores de tempo parcial em um ambiente onde cada colaborador, de sua própria iniciativa, adiciona uma pequena parte para gerar um resultado maior. Segundo o autor, o termo "crowdsourcing" é a união da palavra "multidão", em inglês "crowd" e "terceirização", "outsourcing”.

Para Giardelli (2012, p. 25), o crowdsourcing se dá quando a "multidão se une para criar conteúdo, solucionar problemas ou desenvolver tecnologia ou projetos, compartilhando e unindo ideias e conhecimentos". Para o autor, os amadores são parte fundamental deste processo, o que resultou em um novo tipo de consumidor que participa ativamente da concepção de tudo aquilo que consome;as empresas tem, portanto, que se adaptar a esta realidade e planejar suas ações levando em consideração as expectativas destes consumidores, pois, segundo afirma Howe (2009, p. 06), “os amadores são o combustível do crowdsourcing, e o movimento do software de código aberto deu forma ao fenômeno".

\section{METODOLOGIA}

No caso específico desta pesquisa, a metodologia utilizada é o estudo de caso que, de acordo com o Yin (2001), deve ser baseada em seis tipos de materiais ou fontes:

Documentos - nesta pesquisa, podem ser considerados os materiais criados pelos participantes do projeto The Johnny cash Project.

Registros em arquivo - registros presentes no site do projeto, além do levantamento criado através do site Internet Archive.

Comun. \& Inf., Goiânia, GO, v. 18, n. 1, p. 76-96,jan./jun. 2015 
Entrevistas - não realizadas exclusivamente para esta pesquisa, mas já disponíveis no ambiente da Internet na forma de texto em artigos publicados em sites especializados, além de entrevistas no YouTube e o vídeo disponibilizado pelo projeto no próprio site do The Johnny Cash Project.

Observação direta - trata-se do acompanhamento e catalogação das mais diferentes categorias apresentadas no projeto.

Observação participante - participar do projeto, ainda no ar, para compreendê-lo melhor e se inserir mais profundamente no estudo do mesmo.

Artefatos físicos - Yin aponta, dentre uma diversidade de possíveis artefatos, os "aparelhos de alta tecnologia". Por este motivo, neste item, constarão os aspectos de software tidos como relevantes nas plataformas de participação disponíveis no site do projeto.

Parte do levantamento de dados para o presente estudo de caso buscou vestígios históricos no sistema "Internet Archive" e em sua ferramenta de busca "WaybackMachine". Este recurso permite acesso a mais de 150 bilhões de páginas de Internet gravadas no passado, de milhões de sites diferentes. Para Nicholson (2005), há muitas similaridades na pesquisa através da arqueologia de espaços físicos e da web. Ambas buscam vestígios de ocupações passadas e se baseiam em recuperar, sistematizar, descrever e estudar. Segundo o autor, a busca por estes vestígios pode ser tanto no espaço da web como um todo, através de sistemas de busca, quanto em sistemas organizados de arquivamento; essa busca em bibliotecas de dados online também irá compor parte da coleta de dados sobre o objeto deste estudo.

Arqueólogo é aquele que estuda pedras, pinturas e gravações feitas nas paredes de cavernas, a fim de descobrir parte do passado da história desconhecida, buscando estabelecer relações de sentido históricas a partir da localização de vestígios de sujeitos e sociedades passadas. Da mesma forma, ocupantes e usuários de sistemas digitais deixam artefatos-dados quando interagem com um espaço de informação da web (NICHOLSON, 2005). Segundo o autor, existem diversas similaridades na pesquisa de espaços físicos e da web na busca de vestígios de ocupações passadas. Ambas tratam de "recuperar, sistematizar, descrever e estudar" (NICHOLSON, 2005, p. 01). Silva (2012) aponta que, estes vestígios virtuais, quando coletados, podem fornecer informações valorosas para a investigação, especialmente sobre os tipos de relações, comunidades e culturas que se estabeleceram em torno de um objeto da web.

Além da busca na "WaybackMachine", o presente estudo utiliza-se, também, de recursos dos resultados obtidos através da ferramenta "TouchGraph", que usa decorrências de 


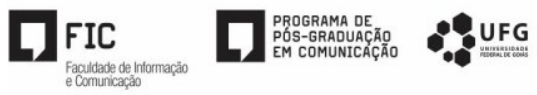

busca do Google para organizar mapas visuais dinâmicos. Assim, o "TouchGraph" consegue formar aglomerados de sites a partir do referenciamento entre eles; quando um nome, tema ou endereço pesquisado aparece em um website, este é incluído no mapa e vinculado ao site em que foi referenciado.

A próximaseção apresentará seu foco na análise dos dados e a descrição do objeto de estudo selecionado, que, conforme explicitado anteriormente, é o projeto denominado The Johnny Cash Project.

\section{ANÁLISE DE DADOS}

The Johnny Cash Project pode ser considerado um projeto de arte coletiva que disponibiliza através de um website interativo, ferramentas que proporcionam aos internautas a possibilidade de criar frames (quadros) para o vídeo da música póstuma "Ain't no Grave" do músico Johnny Cash. Realizado em parceria com o Google Chrome no ano de 2010, o projeto se utiliza de uma ferramenta de desenho disponibilizada no próprio site, na qual os usuários criam quadros que, alinhados em sequência, formam o vídeo da música.

Desde a sua criação, este é um projeto aberto continuamente, possibilitando que os usuários colaborem a qualquer momento, tornando o vídeo diferente a cada exibição. A música “Ain’t no Grave” é a última gravação de estúdio de Johnny Cash e sua letra fala sobre temas como mortalidade, ressurreição e vida em constante transformação, o que a torna condizente com o projeto, já que sua proposta é a de renovação constante e permanente através da participação de novos usuários. De acordo com o documentário exibido pelo RadicalMedia, até o momento, mais de quinhentos e cinquenta mil pessoas de cento e noventa e quatro países já haviam participado do projeto.

The Johnny Cash Project não tem um caráter de relacionamento direto com nenhuma marca, nem mesmo com algum produto específico para venda, apenas com a canção composta por Johnny Cash. Porém, o vínculo emocional, e também afetivo, do usuário com o artista pode ter influenciado a maioria dos internautas a participarem do projeto.

Para colaborar, é necessário que o usuário realize cadastro e escolha a cena a ser "redesenhada". De forma a esclarecer o processo de participação, segue, abaixo, uma célere explicação.

1 - Ao acessar a página do projeto, o usuário se depara com alguns frames já desenhados por outros participantes e algumas abas, traduzidas como "Explorar"; "Contribuir"; "Sobre"; "Créditos"; além de "Registro/Iniciar Sessão" e um breve resumo do

Comun. \& Inf., Goiânia, GO, v. 18, n. 1, p. 76-96,jan./jun. 2015 
projeto, definido pelo próprio site como "um trabalho comunitário único, um retrato vivo do Homem de Preto (Johnny Cash)".

A autodescrição do projeto continua, intitulando-se como algo interativo em constante desenvolvimento e crescimento contínuo; a descrição, ainda, incentiva a participação e colaboração dos usuários:

[...] através deste website interativo, os participantes podem desenhar o seu próprio retrato de Johnny Cash para ser integrado em um trabalho coletivo. $\grave{A}$ medida que as pessoas ao redor do mundo contribuem, o projeto continuará se desenvolvendo e crescendo um quadro de cada vez. Envie seu desenho para se tornar uma parte do novo videoclipe para a música "Ain't No Grave". Unida e retransmitida em sequência, a sua arte, emparelhada com a música sombria de Johnny, se tornará um retrato vivo, em movimento e em constante mudança do Homem de Preto.

2 - Para colaborar com o The Johnny Cash Project, o usuário deve realizar o cadastro, inserindo o campo de e-mail e senha, assim como a sua data de nascimento e localização.

3 - Depois de ter efetuado o cadastro, aparece uma mensagem na tela confirmando o login do usuário.

4 - Ao clicar em "Contribute", a página é redirecionada a uma tela que exibe três frames aleatórios do vídeo, dentre os quais o usuário deve escolher sobre qual deles realizará o processo de rotoscopia.

5 - Após escolher o frame e clicar em "Start Drawing", o usuário é redirecionado a uma tela que indica os atalhos de teclado possíveis: "Shift", "Space" e "Control", todas as outras ações podem ser realizadas com o mouse ou com uma mesa digitalizadora do tipo tablet.

6 - A área de trabalho de criação exibe 8 tipos de pincéis, dentre os quais o usuário pode editar tamanho, opacidade e variação de cor (em escala P\&B), além de desfazer e refazer edições no desenho.

Assim que o quadro estiver finalizado, o usuário que deseja enviar o seu trabalho para o projeto deve clicar em "Submit Frame". Após esse procedimento, o participante é convidado a avaliar o seu desenho em quatro categorias: "Realistic"; "Abstract"; "Sketchy" e "Pointillism". A fim de evitar possíveis problemas, o frame passa por uma moderação antes de ser finalmente aprovado para entrar no projeto. Para explorar os quadros já realizados e assistir ao vídeo, o usuário pode filtrar a timelineem nove diferentes divisões: "HighestRated Frames", "DirectorCuratedFrames", "MostBrushstrokes Per Frame", "MostRecent Frames", 
"Random Frames", além dos já citados "Pointillism Frames", "Realistic Frames", "Sketchy Frames" e "Abstract Frames".

Em depoimento no vídeopromocional do projeto, o diretor Chris Milk ponderou que criou este projeto "para que os fãs de Johnny Cash pudessem criar coletivamente o seu último vídeo musical". Ao discorrer sobre a forma de participação, Aaron Koblin, diretor criativo do "TJCP" junto com Milk, afirma que a colaboração se dá "quadro a quadro", pois "cada pessoa contribui com somente um frame para fazer o seu tributo a Johnny Cash".

O usuário de Diamond Bar, na California, que desenhou o frame \#166, ressalta que quando descobriu o projeto ficou "completamente deslumbrado". Ele complementa, dizendo que precisou voltar mais vezes ao site para rever as artes realizadas por outras pessoas. Já o usuário de Edimburgo, no Reino Unido, que desenhou o frame \#522, disse que havia ficado muito triste com o falecimento de Johnny Cash, mas acreditou que colaborar com o projeto poderia ser interessante. Ele classificou a experiência como uma oportunidade "maravilhosa de poder colaborar em algo que contribua com a memória de Johnny Cash".

Outrausuária(frame\#856),deSãoFrancisco,definequeoprojeto"realmente permite que a última gravação de Cash se transforme em um memorial vivo". Mais tarde, ela descreve sua experiência e se declara "honrada em poder contribuir em um projeto tão mágico". Um participante de Hemet, também na Califórnia (frame \#329), diz experimentar um "sentimento poderoso" ao fazer partede um vídeo colaborado por tantas pessoas. O usuário de Knoxville, no Tennessee (frame \#225), complementa que o projeto proporciona a colaboração de pessoas de diversas partes do mundo, já tendo visto trabalhos de usuários do Japão, Bruxelas e EUA. O usuário de Santa Ana, na Califórnia, classifica o projeto como "orgânico", pois está sempre mudando na medida em que os usuários submetem as suas artes e nunca é o mesmo.

Em entrevista no ano de lançamento do projeto, o diretor Chris Milk, se classifica como muito interessado pelo mercado de vídeos de música (videoclipes), principalmente pelo o que o mercado se tornou, pois, segundo o diretor, houve uma mudança gigantesca no modelo de apresentação de vídeos de música. Para o diretor, antigamente a MTV era a principal vitrine dos videoclipes, e com a interrupção da exibição deles na emissora, todo este mercado foi parar na Internet. Conforme Milk, existem muitas diferenças em realizar um vídeo para a Internet e para a televisão, já que a Internet permite uma interação muito maior do que a TV, que é um canal de "uma via" de comunicação com o telespectador. Segundo o diretor, a Internet permite diversas experimentações e versões de um mesmo vídeo, o que certamente não ocorre com os vídeos transmitidos pela televisão. 
Antes de começar o projeto, Milk relata que se perguntou como "poderia realizar crowdsourcing em um vídeo". Para isso acontecer, ele deveria realizar um vídeo de algum artista sério, para promover a arte e evitar ao máximo o número de brincadeiras de mau gosto no processo de rotoscopia, que dispensaria uma moderação mais forte das artes. Dessa forma, foi até a gravadora que estava finalizando o álbum póstumo do cantor e propôs o projeto. A gravadora que já estava conformada em não poder realizar videoclipes das músicas do disco aceitou. Para Chris Milk, o projeto ficou ainda mais interessante devido ao fato de Johnny Cash estar cantando sobre a sua própria ressureição e possibilidade de vida eterna nos corações de todos os fãs. Para ele, "TJCP" funcionou tão bem justamente por serem estes fãs do artista que geraram o conteúdo e se engajaram no projeto.

Milk diz não considerar o "TJCP" um projeto inovador, pois ele foi criado apenas reutilizando tecnologias já existentes na web, tendo toda a programação na linguagem flash. Ele complementa dizendo que o projeto deu bastante trabalho naprogramação, pois além de nunca repetir os frames, ele pode ser categorizado em“quadros melhores avaliados", ou "últimos quadros realizados". Para o diretor, o maior desafio encontrado na execução do projeto foi o fato de não possuírem muito dinheiro para realizá-lo, refletindo em uma pequena equipe de realizadores.

Através do comentário do diretor, percebe-se que assim que ele sentiu a dificuldade no mercado da indústria de videoclipes, com um espaço cada vez menor na televisão, notou que havia a necessidade de migrar para uma nova mídia, a Internet. Para criar o "TJCP", ele pensou em uma interface funcional e estética, que de acordo com Johnson (2001), auxilia na forma de interação entre usuário e computador, propriedades das chamadas "novas mídias". Lemos (2007) afirma que com as "novas mídias", todos podem participar na produção e circulação da informação, ações que podem ser facilmente identificadas no projeto elaborado por Chris Milk.

The Johnny Cash Project apresenta diversas características de uma plataforma lançada na Web 2.0, pois, baseado em O'Reilly (2007), é um serviço continuamente aberto, que fica melhor quando mais as pessoas o utilizam. Da mesma forma, "TJCP" se mostra uma plataforma participativa, multimídia e que possibilita um caminho de "mão dupla" de comunicação entre os usuários, todas características da Web 2.0 apontadas por Pinho (2000). Melo (2007) defende que não existe nenhuma grande inovação tecnológica nas aplicações da Web 2.0, apenas o reuso das tecnologias já consagradas. Analisando a fala de Chris Milk, 
percebe-se da mesma forma que o projeto não apresentou nenhuma inovação tecnológica, apenas reutilizou as tecnologias já existentes com um novo enfoque.

Classificado pelo próprio diretor como um projeto de crowdsourcing, The Johnny Cash Project apresenta diversas características desse tipo de plataforma. Assim como nas definições de crowdsourcing de Howe (2009) e Giardelli (2012), os amadores são o principal combustível de colaboração do "TJCP". Além de possuir todo o conteúdo feito exclusivamente por usuários (UserGeneratedContent), toda colaboração gerada para o "TJCP" foi dada de forma espontânea e gratuita. Para Smithson (2011), em websites, o UGC é um sinônimo de conteúdo gratuito, pois os usuários não são pagos para gerarem tais conteúdos. Além disso, a "conexão social” defendida por Grannell (2009) é estabelecida com os usuários do projeto através do sentimento de identificação dos fãs com o cantor.

Para uma análise melhor fundamentada, o presente trabalho utilizou-se da ferramenta TouchGraph, que procura os resultados de busca gerados pelo Google para organizar mapas visuais dinâmicos. A seguir, o mapa gerado ao inserir o nome do projeto (The Johnny Cash Project) na plataforma (Figura 1):

Figura1 - Mapa do termo The Johnny Cash Project geradopeloTouchGraph

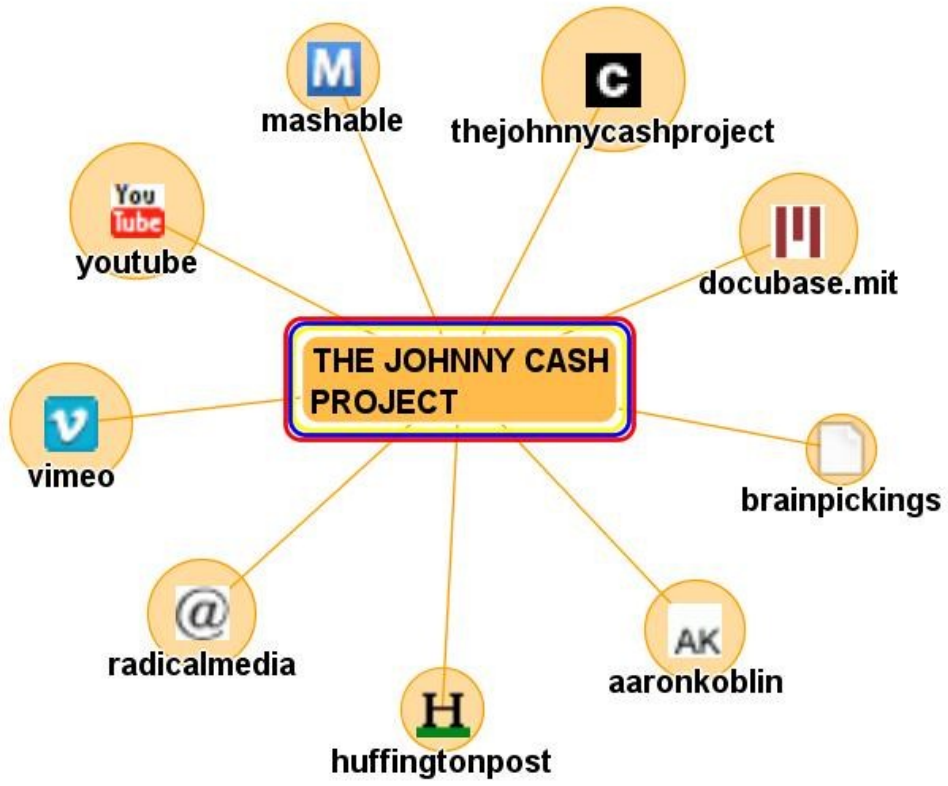

Fonte: TouchGraph (2014)

Quando disposto na plataforma TouchGraph, o termo The Johnny Cash Project é automaticamente conectado a 9 diferentes sites, incluindo o próprio site do projeto, o YouTube e o Vimeo, redes sociais nas quais o "TJCP" está inserido através de canais oficiais.

Comun. \& Inf., Goiânia, GO, v. 18, n. 1, p. 76-96,jan./jun. 2015 
Se os termos "UserGeneratedContent" (UGC) e "Crowdsourcing" forem adicionados na pesquisa de The Johnny Cash Project no TouchGraph, percebe-se que os três termos se unem através do site "Mashable", weblog estadunidense de notícias relacionadas a Internet e mídias sociais. O Site "The Huffington Post", portal de notícias e agregador de blogs americano, ainda relacionou o nome do projeto com o UGC. Nota-se, também, a ausência do Facebook, maior rede social do mundo, com 1,19 bilhões de usuários e a presença do Twitter, rede com 271 milhões de usuários,que possui perfil oficial do projeto. Tais constatações podem ser percebidas no mapa a seguir:

Figura 2 - Mapa de"TJCP", UGC e crowdsourcing gerado pelo TouchGraph

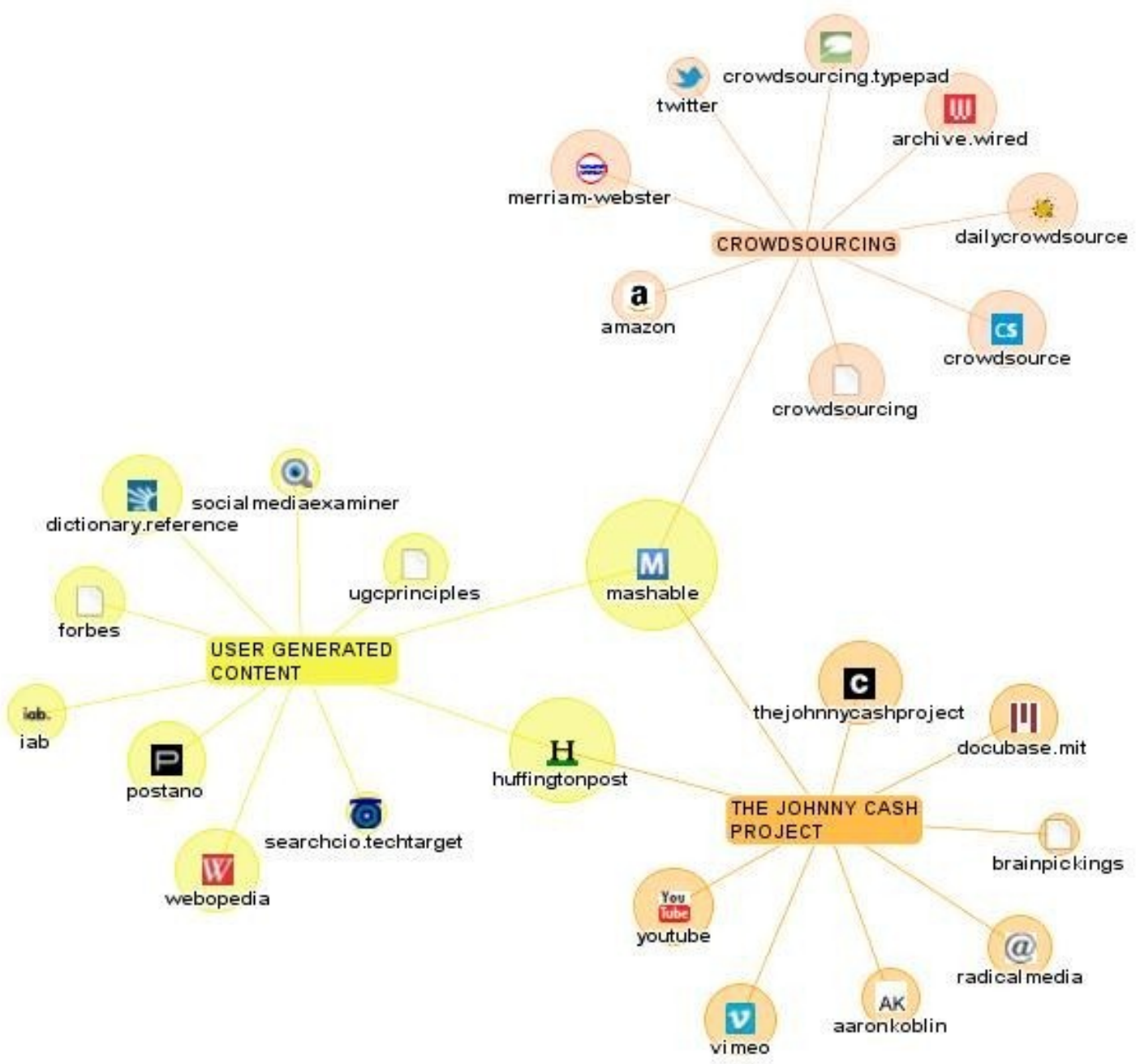

Fonte: TouchGraph (2014)

Além das características anteriormente citadas, o "TJCP" pode ser considerado uma plataforma da Web 2.0, pois proporciona a transferência de conhecimento e emoções entre os fãs, e esta troca é algo onde as pessoas podem facilmente se misturar e se relacionar umas com as outras, assim como defendido por Phillips e Young (2009), que citam tais aspectos 
como característicos da Web 2.0. Primo (2007) destaca que a Web 2.0 apresenta repercussões sociais importantes através da potencialização de processos de trabalho coletivo, criação e produção de informações. Outra característica do projeto é ser uma plataforma que potencializa as mais variadas formas de publicação, compartilhamento e organização de informações. Além disto, ele amplia os espaços de interação entre os participantes do processo ao migrar para outras plataformas, como o YouTube.

Ao inserir o termo The Johnny Cash Project no YouTube, além do canal oficial do projeto, percebe-se diversos vídeos exportados da plataforma original pelos próprios usuários, sendo que são, obviamente, todos diferentes e provenientes de diversos anos.

Ao analisar os vídeos exportados da plataforma para sites como o YouTube e o Vimeo, notou-se eles haviam atingido uma nova parcela de usuários; aqueles que não tinham participado do The Johnny Cash Project na plataforma original, mas que foram afetados pelos vídeos exportados pelos fãs. O índice de aprovação por parte dessa nova parcela de usuários foi alto, podendo ser percebido através de comentários positivos e números de "likes" superior aos "dislikes".

Através dos comentários dos participantes, é possível verificar que os usuários estão espalhados por diversas localidades do mundo, assim observado pelo usuário do Tennessee no vídeo promocional do projeto. Canclini (2008) acredita que uma das causas da desterritorialização na web se dá por causa da interatividade, já que a web facilita a socialização dos internautas, ao mesmo tempo que os "desconexa socialmente", quando há a preferência das pessoas em ficarem em frente aos computadores do que relacionando-se fisicamente em "lugares localizados".

Ao analisar o projeto, percebe-se um nível elevado de engajamento por parte dos colaboradores. Oficialmente, a plataforma original não permite a exportação das versões dos vídeos criados pelos participantes. Dessa forma, todos os vídeos presentes no YouTube em perfis de usuários foram exportados de forma "não-oficial" do site "TJCP". Assim, percebe-se que o sistema do projeto vai muito além daquilo que foi previsto inicialmente pelos realizadores, moldando-se aos desejos enecessidades dos usuários. Na medida em que existem diferentes versões de vídeos provenientes de The Johnny Cash Project disponíveis no YouTube, o presente trabalho utilizou-se de recursos da Web 2.0, como a troca de mensagens em comentários do próprio YouTube, para descobrir de que forma os participantes conseguiam exportar os vídeos da plataforma original. 
Assim, descobriu-se, segundo o relato do usuário@joerossu, que existem muitas maneiras de exportar o vídeo da plataforma original do "TJCP". Além de poder utilizar addons do navegador de Internet e realizar downloads via programas externos, também há a possibilidade de, apenas, se utilizar do link obtido no código-fonte do site do projeto. Devido ao seu alto grau de engajamento com o "TJCP" e a sua disponibilidade, o usuário @joesossu foi escolhido para responder algumas perguntas sobre o projeto e sua participação.

Sobre sua motivação para a participação no “TJCP”, o usuário @joerossu salienta que é "um grande fã" de Johnny Cash e que na primeira vez que ouviu sobre o projeto, precisou visitá-lo. Para ele, está é a forma de manter o cantor vivo para ele próprio e para as próximas gerações. O usuário credita a sua familia (seu pai e avô) a responsabilidade de ter se tornado um fã de Johnny Cash. Emquantidade de participação, @joerossu diz ter colaborado entre 5 a 6 vezes (número que considera baixo), mesmo não sendo um designer profissional (ele é policial). Além disso, o usuário, que mora na Eslováquia, diz não conhecer mais ninguém pessoalmente - além de seu pai -, que tenha participado do projeto. Para ele, o projeto possibilita a reunião de fãs de Johnny Cash espalhados pelo mundo em um só lugar. Ele ainda cita o diretor do projeto, Chris Milk, que fala queThe Johnny Cash Project é um testemunho visual de como o Homem de Preto continua vivo - não apenas através de seu vasto legado musical, mas, nos corações e mentes de todos ao redor do mundo que foram “tocados" pelo seu talento, sua paixão e seu espírito indômito.

Analisando essas novas respostas do usuário@joerossu, é possível confirmar o elevado nível de engajamento que o projeto proporciona aos participantes. Primeiro, porque o usuário participou de 5 a 6 vezes do projeto, número razoável de participações, mas que ele considera baixo. Segundo, porque o usuário que "burlou" o sistema da plataforma original e publicou versões no YouTube, conhece o diretor Chris Milk e está tão inteirado acerca do projeto a ponto de parafrasear o diretor na hora de decrever sua opinião sobre o "TJCP". Para ele, a plataforma interativa do projeto é uma oportunidade para aproximar as novas gerações de Johnny Cash. Percebe-se também, que o usuário @joerossu pode ser identificado como um prosumere, mesmo sendo um policial em seu país, está sempre à procura de novos conhecimentos e desenvolvendo novas competências nos seus aspectos de interesse, como a criação de remixes de músicas para alguns artistas na Eslováquia. Da mesma forma, observando os principais atributos de um prosumer, além de engajado, o usuáriopode ser identificado como um comunicador, por dividir com outras pessoas a sua experiência; ele é, 
também, influenciador, por ser fonte de opinião para outros participantes e orgulhoso, por não ter medo de experimentar.

A fim de conceber um apoio quantitativo à análise do objeto de estudo, o presente trabalho utilizou-se da coleta de dados realizada através da utilização da metodologia de arqueologia da Internet. Isto se deu pelo fato do projeto ter sido lançado em 2010, e, portanto, não existem registros atuais de apoio quantitativo nasmídias especializadas. No entanto, este projeto foi escolhido devido ao expressivo número de usuários cadastrados e por se tratar de uma iniciativa de participação coletiva a nível mundial que se estende até hoje.

No caso da coleta de dados para o projeto The Johnny Cash Project, a ferramenta "WaybackMachine" apresenta registros desde 20 de abril de 2010, ano de inauguração do projeto na web. Nenhum dos registros coletados historiou alguma interface do projeto diferente da atual, indicando que o projeto só foi ao ar depois de finalizado.

Através da análise da imagem gerada pelo "WaybackMachine", é possível visualizar que o pico de acessos ao projeto se deu entre o período de outubro de 2010 a fevereiro de 2011. A primeira data de registro se dá em abril de 2010, sendo que o projeto só foi lançado oficialmente em setembro, data de aniversário de falecimento do cantor. Possivelmente, o pico de acessos da plataforma no mês seguinte ao seu lançamentose dá devido à quantidade de divulgação do projeto em sites e veículos de imprensa especializados.

O interesse contínuo dos participantes no "TJCP" tem ligação direta com a relação que se estabelece entre os usuários do projeto e os fãs do cantor. À medida que o projeto já possui quatro anos de existência e não apresenta o intuito de ser encerrado por parte dos criadores, pode-se projetar que o número de interações ainda deve se manter por bastante tempo. Aliado a isso, está o fato de que o projeto, mesmo feito em 2010, ainda se mantém atrativo e "moderno" aos olhos dos participantes. Se utilizando da colaboração via UserGeneratedContent, que, de acordo com Smithson (2011), é o segmento de crescimento mais rápido na Internet, o"TJCP" ainda se mantém atual e deve continuar recebendo participações ao longo dos próximos anos. Devido à sua estrutura democrática, onde todos os interessados podem colaborar e contribuir para a evolução da plataforma, The Johnny Cash Project tende a evoluir pelo uso de seus participantes, justamente por ter sido desenvolvido em um ambiente que permite e incita a colaboração e a integração de novos usuários.

\section{CONSIDERAÇÕES FINAIS}


Inegavelmente, o modo de interagir na Internet tem evoluído com o passar dos anos. Com as possibilidades de interação e colaboração proporcionadas pelo surgimento da Web 2.0, surgem novas plataformas que se utilizam das características dessa nova rede para transformar o processo de colaboração por parte dos usuários.

A presente pesquisa possuía como principal propósito descobrir como se dão as dinâmicas de colaboração na Web 2.0 através da coautoria dos usuários no The Johnny Cash Project. Chegou-se a percepção de que a força da coletividade e engajamento na Web 2.0potencializa-se através de ferramentas como o crowdsourcing, com força suficiente para alterar os paradigmas do processomidiático, relacionamento entre usuários e até mesmo influenciar no consumo de bens culturais, como os videoclipes de música.

À medida que este trabalho foi desenvolvido, através do estudo de caso de The Johnny Cash Projectm foi possível perceber que o projeto lançado em 2010 por Chris Milk e Aaron Koblin através da ferramenta de crowdsourcing, foi desenvolvido para instigar a colaboração, a interatividade e para gerar relacionamento entre os usuários. De certa forma, é interessante observar que um músico como Johnny Cash, falecido há mais de 10 anos, ainda provoque e motive seus fãs a se engajarem e produzirem juntos um material novo inspirado no cantor.

Por se referirem a fenômenos relativamente recentes, não é possível assegurar que todos os conceitos abordados nesta pesquisa se mantenham inalteráveis ao passar do tempo. Embora se tenha conseguido chegar a uma análise convincente, este estudo deixa, ainda, alguns questionamentos futuros: será que, de fato, a colaboração na web irá se solidificar como ferramenta agregada às maneiras tradicionais de geração de conteúdo e continuará exercendo influência nas mais diversas formas de consumo da sociedade? Ou trata-se de, apenas, mais uma "onda", como tantas outras que surgiram na Internet e foram superadas pelas novidades quase diárias que surgem neste ambiente?

Acredita-se que estas e outras questões podem ser respondidas com o aprofundamento das investigações em novas pesquisas e no acompanhamento de The Johnny Cash Project e de outras iniciativas de crowdsourcing presentes no ambiente da Web 2.0.

\section{REFERÊNCIAS}

ANDERSON, C. A cauda longa: do mercado de massa para o mercado de nicho. Rio de Janeiro: Campus, 2006.

BRABHAM, D. C. Crowdsourcing. Cambridge: MIT Press EssentialKnowledge, 2013. Disponível em: <http://goo.gl/LLXKWg>. Acesso em: 26 set. 2014. 
CANCLINI, N.G. Leitores, espectadores e internautas. São Paulo: Iluminuras, 2008.

CASTRO, M. Colaboração online: a Internet a serviço da criação. Revista Exame, São Paulo, fev. 2011. Disponível em: <http://exame.abril.com.br/rede-de-blogs/midias-sociais/tag/colaboracaoonline/>. Acesso em: 18 set. 2014.

FRAGOSO, S. De interações e interatividade.Revista Fronteiras Estudos Midiáticos, São Leopoldo, v. 3, n. 1, p. 83-95, 2001.

GIARDELLI, G. Você é o que você compartilha: e-agora: como aproveitar as oportunidades da vida e trabalho na sociedade em rede. São Paulo: Gente, 2012.

GRANNELL, C. The psychology of user-generated content.MarketingMagazine, UK, p. 64-66, set. 2009. Disponível em: $<$ http://www.grannellmarketing.com/articles/MM-UGC.pdf $>$.Acesso em: 15 out. 2014.

HOWE, J. O poder das multidões: porque a força da coletividade está remodelando o futuro dos negócios. Rio de Janeiro: Elsever, 2009.

IBGE. Pesquisa Nacional por Amostra de Domicílios. 2013. Disponível em: $<\mathrm{ftp} / / / \mathrm{ftp}$. ibge.gov.br/Trabalho_e_Rendimento/Pesquisa_Nacional_por_Amostra_de Domicilios_anual/2013/Sintese_Indicadores/sintese_pnad2013.pdf $\$$. Acesso em: 07 nov. 2014.

IBOPE. Brasil é o terceiro país em número de usuários ativos na internet. 2013. Disponível em: $<\mathrm{http} / /$ www.ibope.com.br/pt-br/noticias/Paginas/Brasil-e-o-terceiro-pais-em-numero-de-usuariosativos-na-internet.aspx >. Acesso em: 25 ago. 2014.

JOHNSON, S. Cultura da interface: como o computador transformanossa maneira de criar e comunicar. Rio de Janeiro: Jorge Zahar, 2001.

LEMOS, A. Anjos interativos e retribalização do mundo: sobre interatividade e interfaces digitais. [S.l.: s.n.], [2010]. Disponível em: <http://www.facom.ufba.br/ciberpesquisa/lemos/interativo.pdf>. Acesso em: 16 set. 2014.

LÉVY, P. A inteligência coletiva: por uma antropologia do ciberespaço. 5. ed. São Paulo: Loyola, 2000.

LIMEIRA, T. M. V. E-Marketing: o marketing na internet com casos brasileiros. São Paulo: Saraiva, 2003.

MARQUES, J. A.; CARDOSO, C. M. Interatividade: conceitos e aplicações. In:Sociedade Brasileira de Estudos Interdisciplinares da Comunicação, 34, 2011, Recife.Anais... Recife:Universidade Católica de Pernambuco, 2011. p. 1-15. Disponível em:

$<$ http://www.intercom.org.br/papers/nacionais/2011/resumos/R6-2407-1.pdf $>$. Acesso em: 16 set. 2014.

MELO, C. S. de. Web 2.0 e Mashups: reinventando a internet. Rio de Janeiro: Brasport, 2007.

MOURA, P. O Poder do engajamento através da promoção nasplataformas sociais. In:MOURA, P. Comunicação e marketing digitais: conceitos, práticas, métricas e inovação. Salvador: Edições VNI, 2011. Disponível em: <http://www.rp-bahia.com.br/biblioteca/e-books/cmktdigitais2011.pdfs .

Acessoem: 15 set. 2014.

NICHOLSON, S. A framework for Internet archeology: discovering use patterns in digital library and web-based information resources. Chicago: First Monday, 2005.

Comun. \& Inf., Goiânia, GO, v. 18, n. 1, p. 76-96,jan./jun. 2015 
O’REILLY, T. What Is Web 2.0.Sebastopol: O’Reilly media, 2005. Disponível em: $<$ http://oreilly.com/web2/archive/what-is-web-20.html>. Acessoem: 17 mai. 2014.

PHILLIPS, D.; YOUNG, P. Online public relations:a practical guide to developing an online strategy in the world of social media. London: Kogan Page, 2009.

PINHO, J. B. Publicidade e vendas na Internet: técnicas e estratégias. São Paulo: SUMMUS, 2000.

PINK, D. H. Drive: the surprising truth about what motivates us. Londres: Penguim Books, 2009.

PRIMO, A. O aspecto relacional das interações na web 2.0. Brasília: E-Compós, 2007.

RECUERO, R. Redes sociais na Internet. Porto Alegre: Sulina, 2009.

SANTAELLA, L. Navegar no ciberespaço: o perfil cognitivo do leitor imersivo. São Paulo: Paulus, 2004.

SILVA, A.C.What's up guys!?Mysteryguitarmanhere! Designestratégico e comunicação na construção do sistema-produto audiovisual na internet. Porto Alegre: Universidade do Vale do Rio do Sinos, 2012.

SMITHSON, P. User generated content report: The growing phenomenon that is changing the way we publish and consume media on-line. 2011. Disponível em:

$<$ http://www.smashwords.com/extreader/read/239342/7/user-generated-content-report $>$. Acesso em: 06 out. 2014.

TAPSCOTT, D.; WILLIAMS, A. Wikinomics:como a colaboração em massa pode mudar o seu negócio. Rio de Janeiro: Nova Fronteira, 2007.

THOMPSON, J. B. A mídia e a modernidade: uma história social da mídia. 5 ed. Petrópolis: Vozes, 2002.

YIN, R. K. Estudo de Caso: Planejamento e Métodos. São Paulo: Atlas, 2001.

Recebido em:24/01/2015

Aceito em: $19 / 03 / 2015$

Publicado em: 15/06/2015 